\title{
Interrogando los sentidos de Identidad: Un encuentro entre subjetividades y retratos pictóricos del s. XIX en la Universidad
}

\author{
José Eugenio Rubilar Medina \\ Doutorando Artes y Educación \\ Universidad de Barcelona
}

\section{RESUMEN}

Este articulo decanta de un punto de fuga de una investigación más amplia llevada a cabo junto a estudiantes del grado de Pedagogía en Artes Visuales con quienes fuimos trazando una deriva exploratoria para indagar sobre los sentidos y nociones que orbitan a la compleja noción de Identidad. En el marco de esta investigación, (aún en desarrollo), reconstruyo lo que supuso una experiencia de indagación, colaborativa e inclusiva, en la que la materialidad (retratos del S.XIX pertenecientes a la colección de obras pictóricas del Museo de la Universidad) se inscribió como un agente mediador que permitió releer conceptos, nociones, saberes y deseos para repensar(nos) y co-construir conocimiento desde lo intersubjetivo en la Universidad. En este ejercicio de reflexividad, situada y encarnada, se toma distancia de los esquemas de análisis semióticos adscritos a lecturas descriptivas, tampoco se establecen estrategias de codificación y categorización que fragmenten, segmenten y tematicen las experiencias de indagación. Este texto es el despliegue de una trayectoria donde docentes y estudiantes nos abrimos a la posibilidad de explorar, creativamente y desde un sentido de devenir, los propios procesos de subjetivización identitaria atendiendo a los encuentros con la materialidad.

PALABRAS CLAVE: Identidad, Subjetividad, Universidad, Materialidad

\section{ABSTRACT}

This article is the culmination of a broader research project carried out with students of the Visual Arts Education degree, with whom we traced an exploratory drift to investigate the senses and notions that orbit the complex notion of Identity. Within the framework of this research, (still in development), I reconstruct what was a collaborative and inclusive experience of investigation, in which materiality (19th century portraits belonging to the collection of pictorial works of the University Museum) was inscribed as a mediating agent that allowed us to re-read concepts, notions, knowledge and desires in order to re-think and co-construct knowledge from the intersubjective at the University. In this exercise of reflexivity, situated and embodied, a distance is taken from the schemes of semiotic analysis ascribed to descriptive readings, nor are strategies of codification and categorization established that fragment, segment and theme the experiences of inquiry. This text is the unfolding of a trajectory where teachers and students open up to the possibility of exploring, creatively and from a sense of becoming, the very processes of identity subjectivization by attending to the encounters with materiality.

Keywords: Identity, Subjectivity, University, Materiality 


\section{Situando el contexto formativo universitario}

Las constantes transformaciones que acontecen en todas las dimensiones sociomateriales de la vida contemporánea no son ajenas al dinamismo de los contextos académicos y formativos. En este paisaje de cambios, los debates respecto al papel de la Universidad en la sociedad actual no dejan de estar presentes. En un esfuerzo por asumir las exigencias coyunturales, la Universidad ha promovido ajustes que inciden en los modelos formativos, abarcando el rediseño de planes de estudio, las actualizaciones en las metodologías de enseñanza-aprendizaje, los procesos evaluativos, la reflexión pedagógica, el rol docente, entre tantos otros esquemas adscritos a la tradición educativa universitaria. Sin embargo, estos cambios han propiciado el levantamiento de modelos contractuales más maleables y adaptados a las demandas del contexto productivo y las necesidades de mercado (Montenegro \& Pujol, 2013:233). De lo anterior, el valor de una experiencia universitaria alineada al beneficio económico, convoca a que docentes/ investigadores y estudiantes reflexionemos sobre el rol de la Universidad desde distintos espacios formativos. No se trata únicamente de priorizar el logro de aprendizajes para que los estudiantes sean expertos en determinadas áreas del conocimiento, sino también, apelar al desarrollo de una experiencia de lo común que amplíe las miradas y los espacios de actuación en términos sociales, culturales (Martín-Barbero, 2003:14) y materiales.

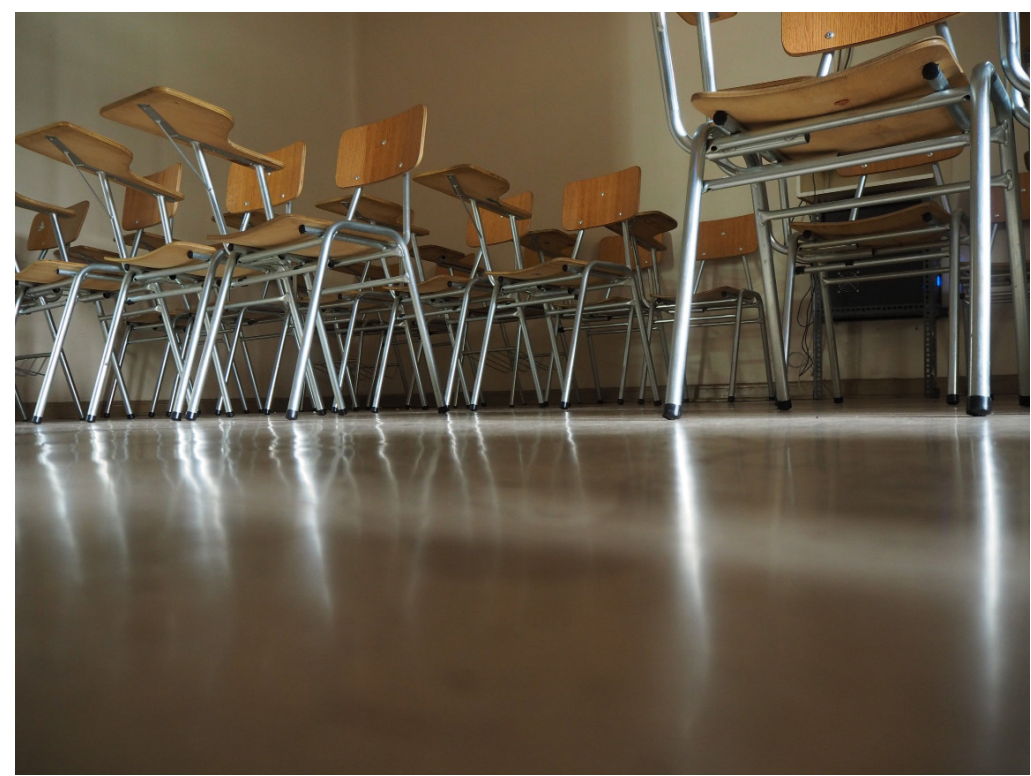

FOTO 1 Disposición de mobiliario en un aula Universitaria

Esto implica restarse de la petición neoliberal que exige la expertise del estudiantado respecto a ciertas competencias para una mejor posición laboral y productiva, pero asimismo, nos alienta a reorientar el desempeño autónomo propiciando instancias de autoaprendizaje reflexivo (Cisterna, Soto \& Rojas, 2016:303) donde se desplieguen habilidades éticas y relacionales adscritas al diálogo y el intercambio mutuo para repensar, colectiva y críticamente, las cuestiones que inciden en los modos de aprender (Hernández \& Miño, 2012:11). De este modo, facilitar el cuestionamiento personal, institucional y social en el horizonte de una Universidad más participativa y democrática.

Una educación que valora el intercambio entre saberes y los pone en relación con los entornos sociomateriales, la cotidianeidad y las subjetividades, estaría promoviendo el desarrollo de estrategias de resistencia, por ende, una respuesta crítica, creativa y formativa a las lógicas del conocimiento único y estandarizado propias del capitalismo cognitivo, pero a la vez, iría abriendo los caminos del estar, ser, pensar, mirar, escuchar, sentir y vivir con sentido decolonial (Walsh, 2014:7) la proyección al futuro. Iniciativas formativas que replantean el lugar y el sentido de los roles establecidos en las dinámicas pedagógicas, son las mismas que propician el rol protagónico del estudiantado enfatizando el sentido de compromiso y la co-responsabilidad. Desde aquí, es posible recrear espacios de diálogo en los que se respeten las singularidades y se celebren las diferencias (Susinos \& Parrilla, 2013:90), reconociendo en la diversidad, una oportunidad para valorar el pluralismo que debate la realidad en cuanto a preceptos fijos, homogeneizantes y hegemónicos (Hernández, 2000:42), pero también, acogiendo aquello que nos afecta (Fonseca, 2011:56). Propuestas de un proyecto formativo inclusivo, colectivo y de intercambio que dé cabida a situaciones abiertas a la exploración, la experimentación, la indagación y el encuentro entre subjetividades y materialidades.

\section{Cuestionando la noción de Identidad}

Ahondar nuestra mirada en la acción educativa artística, sin desentendernos de los fértiles terrenos del hacer y el deshacer, es un apremio a repensar, permanentemente, nuestras acciones y toma de decisiones para interrogar(nos) respecto a lo que hacemos, evaluando las prácticas pedagógicas, los procesos creativos y socializadores, las experiencias de aprendizaje y el lugar de lo material en la Universidad. En estas líneas, se expone una indagación que emerge como el punto de fuga de una investigación más amplia. Una experiencia adscrita al planteamiento y desarrollo de un proyecto formativo que posibilitó el encuentro entre materialidades y subjetividades. A partir de la invitación de la docente a cargo de una asignatura de la especialidad didáctica, compartí una propuesta de trabajo situado junto a las(os) estudiantes del penúltimo curso del grado de Pedagogía en Artes Visuales para realizarla en el espacio institucional del museo universitario (Pinacoteca). De este modo, emergió 
una red de acción e intercambio inclusiva, dinámica y, un tanto didáctica, en la que se intersectaron cuerpos, objetos, espacios, imaginarios, tensiones, controversias e incertidumbres. Un despliegue que, a modo de deriva, nos llevó a una exploración del espacio museal para encontrarnos (o que nos re-encontraran) los retratos decimonónicos expuestos en las salas y son parte de la colección pictórica que se exhibe de forma permanente. Caminando, deteniéndonos, sentándonos y, en la medida que nos hacíamos parte de ese espacio museal, comenzar a habitarlo para levantar interrogantes respecto a una inquietud común: la identidad.

En el acontecer cultural y sociomaterial, las cuestiones en torno a la noción de identidad siguen generando un terreno de exploración que, en sí mismo, no es ni más claro ni más difuso pero, que sin duda, suscita debates atingentes e interesantes de profundizar. La identidad, en su amplitud y complejidad, no puede restringirse al escrutinio de una definición acotada que no genere discusiones. Su estudio, es un campo extenso que ha sido trazado por distintas tradiciones de pensamiento, abarcando las nociones de sujeto hasta aquellos constructos que buscan explicar la praxis social, enredándose en un entramado histórico, biológico, cultural y sociomaterial. Una complejidad que se agudiza si se hace alusión a los conceptos que nos trastocan y encarnamos en términos identitarios: género, sexualidad, raza, religión, etnicidad, nacionalismo, inmigración, movimientos sociales (Brubaker \& Cooper, 2001:6). De lo anterior, el panorama teórico se desenvuelve en una amplitud de postulados y debates académicos que ofrecen un precedente colmado de conceptualizaciones, aproximaciones y reflexiones epistemológicas para delinear a las identidades como múltiples, inestables, negociadas, fragmentadas, fluidas, relacionales, situacionales, contingentes, construidas, etc. (Briones, 2007:60).

Los aportes de la Teoría Crítica Feminista y los Queer Studies, han abierto nuevas discusiones en torno a la noción de identidad, posicionamientos político-sociales que interrogan la formación y producción de sujetos en base al género, politizando la identidad, la subjetividad y los procesos de identificación (Restrepo, 2014:111). Desde aquí, emerge todo un campo teórico, político y artístico que recoge las interrogantes identitarias, para abrir espacios indagatorios en torno a las relaciones entre construcción de subjetividades, identidades y otredades (Arfuch, 2005:14). En esta lógica, el análisis de las identidades no se restringiría únicamente a la identificación de cuáles son las posiciones del sujeto o cómo éstas se han llegado a producir en momentos determinados sino, además, conllevan al análisis de cómo las subjetividades se articulan, o no, a estas interpelaciones desde ciertas posiciones de sujeto (Restrepo, 2014:105). El reconocimiento de los procesos de subjetivación individuales y colectivos (Cano, 2018:48), invitan a desenvolver y remecer los entramados ontológicos para ampliar sentidos en la comprensión de la subjetividad en su pluralidad y polifonía (Guattari, 1992:11). Un trabajo que se constituye en la propia subjetividad, como ejercicio ético y ontoepistemológico de reconstruirse, pensarse, reevaluarse y reubicarse en el lugar de la crítica, no solo como autoevaluación, sino desde la posibilidad de interrogar(nos) (Martínez, 2014:67).

\section{Propuesta metodológica: Encuentros entre materialidades y subjetividades.}

El proyecto formativo (indagatorio) se estructuró en tres fases. Por tratarse de un ejercicio de exploración, se propició un inicio individual para luego dar lugar a un intercambio colectivo. Asimismo, nos propusimos reconocer y anular cualquier forma de normalización (Ball, 1993:28) que hiciera que nuestras subjetividades se subrogasen a algún precepto fijo y/o homogeneizante que remitiera a una relación direccional y/o hegemónica.

\subsection{Derivas exploratorias.}

En una primera instancia, recorrimos las salas de la colección permanente de la Pinacoteca. Abrimos la posibilidad de fotografiar aquellas obras (retratos) que despertaran en nosotras(os) alguna inquietud respecto a la noción de identidad. Ese deambular por las salas, observando retratos pictóricos, se articuló como una deriva epistemológica donde cada cual sitúo sus propias interpretaciones, posibilitando así, cuestionar, redefinir y producir concepciones encarnadas en la reconstrucción reflexiva y crítica de la propia experiencia. Es aquí, donde los retratos se inscriben como agentes mediadores que hacen posible la reconstrucción, un llamamiento a repensar la identidad. Este espacio de exploración y observación, implicó una búsqueda personal y autodirigida para, desde la materialidad/visualidad, interrogar la construcción de identidad(es) apelando a la experiencia sensible (Rancière, 2010).

\subsection{Las cartografías como método de indagación.}

En una segunda fase, se articuló un ambiente de trabajo que puso foco en las posibilidades de las cartografías. Una disposición performativa que nos ubicó en red en el mismo espacio museal, predisponiéndonos a las posibilidades del intercambio y, de este modo, ir hilvanando un mapa para que nuestras subjetividades conectaran con temas, experiencias, inquietudes, imágenes, objetos, etc. Una experiencia intersubjetiva que invita a superar las fronteras disciplinares levantando rutas alternativas que impugnen la autoridad y la segregación de las representaciones hegemónicas, permitiéndonos así, ampliar las formas de expresión, creación y co-construcción de conocimiento en la Universidad.

Este método, movedizo, plural y descentralizado, permitió abrir relecturas que, desde lo material, nos hiciera avanzar más allá de las formalidades estéticas, dando cabida a diálogos que trascendieran las distinciones dicotómicas como lo bello y lo feo, la teoría y la práctica, el sujeto y 


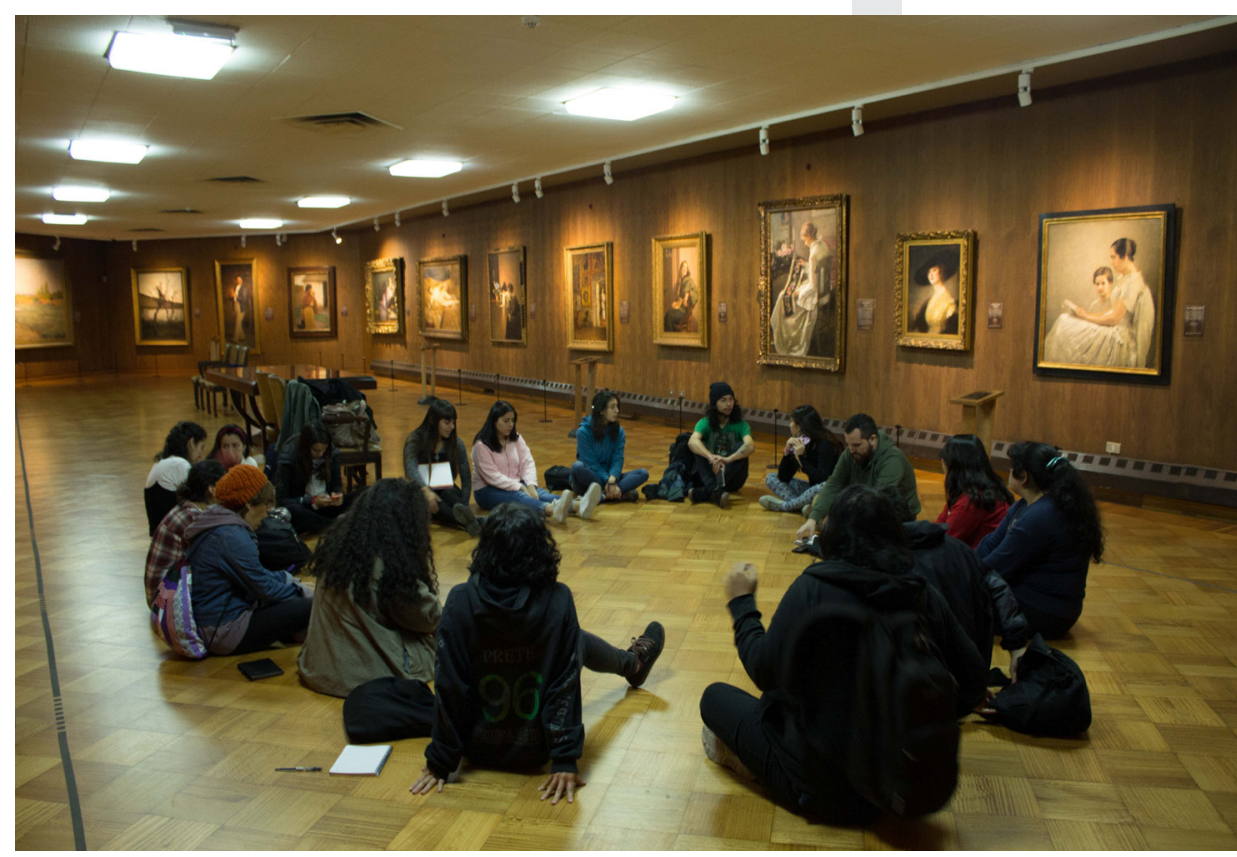

FOTO 2. Disposición performativa en sala de exhibición.

el objeto, el proceso y el resultado, entre otras tantas clasificaciones que terminan por restringir nuestros sentidos, experiencias y relaciones. En la creación de estas cartografías, la experiencia vivida (Van Manen, 2003) se enreda con las subjetividades, cuerpos, retratos, textos, situaciones, afectos, movimientos, encrucijadas, ideas, formas de hacer, etc. que, alineadas a una ontología procesual, relacional y performativa del devenir (Hernández, 2018:112), permiten entretejer conexiones entre conceptos e ideas en movimiento, haciendo que emerjan otras líneas de fuga que no se atrapen, sino que se expandan y generen nuevas formas de praxis a la hora de pensar la identidad y nuestros procesos de subjetivización. Una estrategia colectiva, inclusiva y abierta a la experimentación y la reflexión en los procesos de aprendizaje e indagación en educación artística universitaria.

\subsection{Dar cuenta} de la experiencia.

La última fase no se situó como un cierre, sino como una invitación a crear y compartir las experiencias sobre las recolocaciones, tensiones, agenciamientos, tránsitos e implicancias que supuso repensar la identidad desde los retratos pictóricos. Se invitó a las(os) estudiantes a realizar un objeto digital en el que interrogasen su propia subjetividad reflexionando sobre lo que supuso la experiencia

FOTO 3. Detalle cartografía como método de indagación formativa con perspectiva de futuro. Esta instancia, no solo de recapitulación, permitió que nos detuviéramos a repensar colectivamente aquellos cuestionamientos que emergían alrededor de los retratos y obras pictóricas con las que dialogábamos. Un ejercicio de reflexividad que incitó a las(os) estudiantes a atreverse a recorrer caminos alternativos y realizar otras matizaciones del aprehender: mirar y mirarse (Hernández, 2006:27) desde los retratos para transitar por los márgenes del (auto) conocimiento en la Universidad.

\section{Reflexiones finales:} Identidad, subjetividad y el

\section{lugar de la materialidad.}

La experiencia de hablar desde la visualidad/materialidad de los retratos, abrió interrogantes respecto a los procesos identitarios encarnados, ese ejercicio ético de reconstruirse, pensarse, re-evaluarse y preguntarse en relación a lo que, usualmente, creemos sobre nosotras(os) mismos (Martínez, 2014:29), pero también para analizar lo que hacemos desde nuestros conflictos, costumbres y convenciones (Gergen \& Gergen, 2011:53). Un movimiento de pensamiento que posibilita co-producir nuevas miradas y volver a esos recorridos que se van descubriendo y dejan señales de los acontecimientos, tensiones y agenciamientos que replantean nuestra comprensión de lo que atraviesa nuestra subjetivización. Un proceso en el cual se confrontaron los márgenes de nuestras locaciones, posiciones y conexiones frente a un conjunto de elementos heterogéneos (Grau, Iñiguez \& Subirats, 2010:64): sujetos, espacios, objetos, retratos pictóricos, etc. En los términos de Bonino (2003):

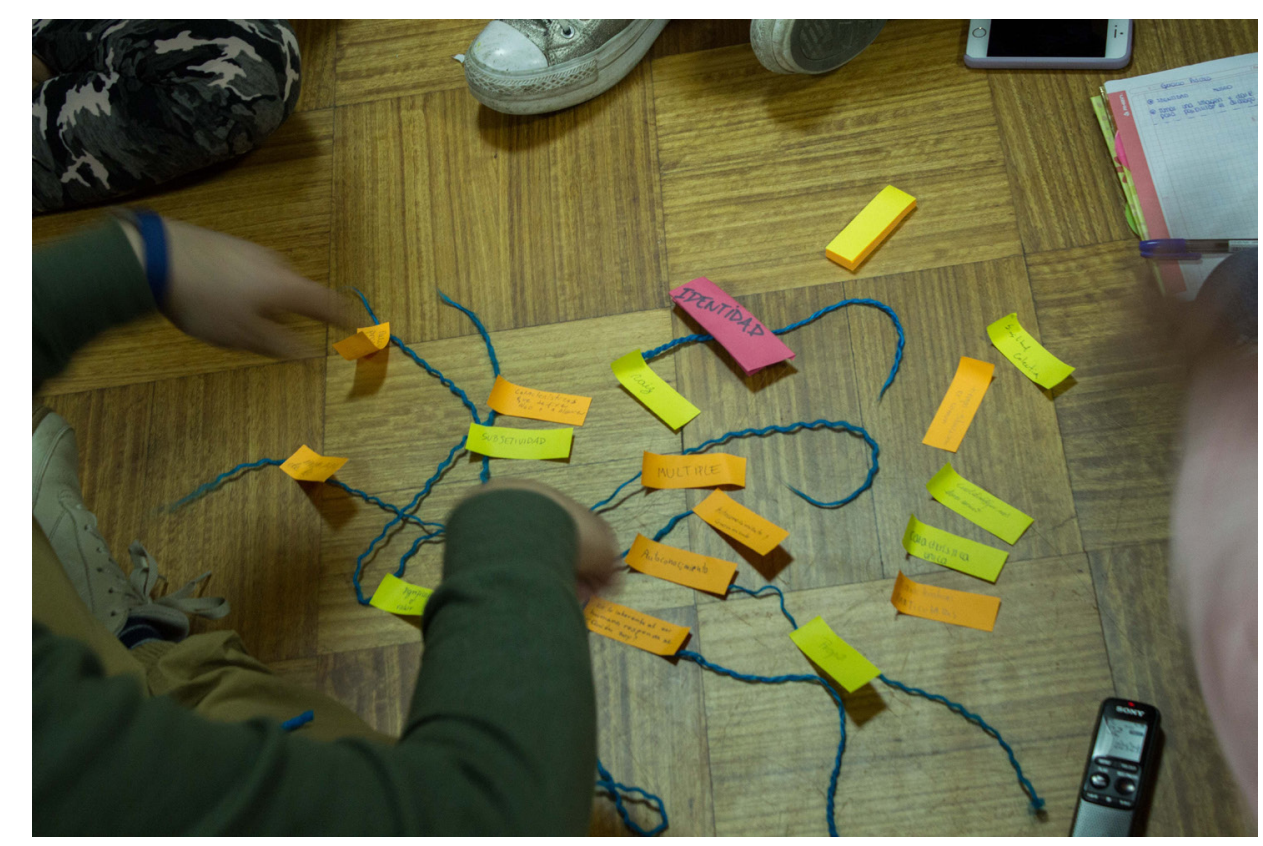


"no tanto en los discursos, sino en las prácticas; no tanto en comportamientos aislados sino en la posición existencial, modo de estar e incapacidad para el cambio en lo cotidiano; no tanto en los momentos estables, sino en las situaciones críticas; en la identidad representacional (imagen de sí) pero especialmente en la funcional (lo que hacemos) (:8)".

Desde aquí, "las producciones de significado dejan de ser las meras prácticas de comunicación entre actores humanos y no humanos o entre lo cultural y lo natural y se convierte en las fuentes efectivas de creación de orden y realidad" (Tirado \& Domènech, 2008:58). Nuestras subjetividades no derivan de situaciones o estados

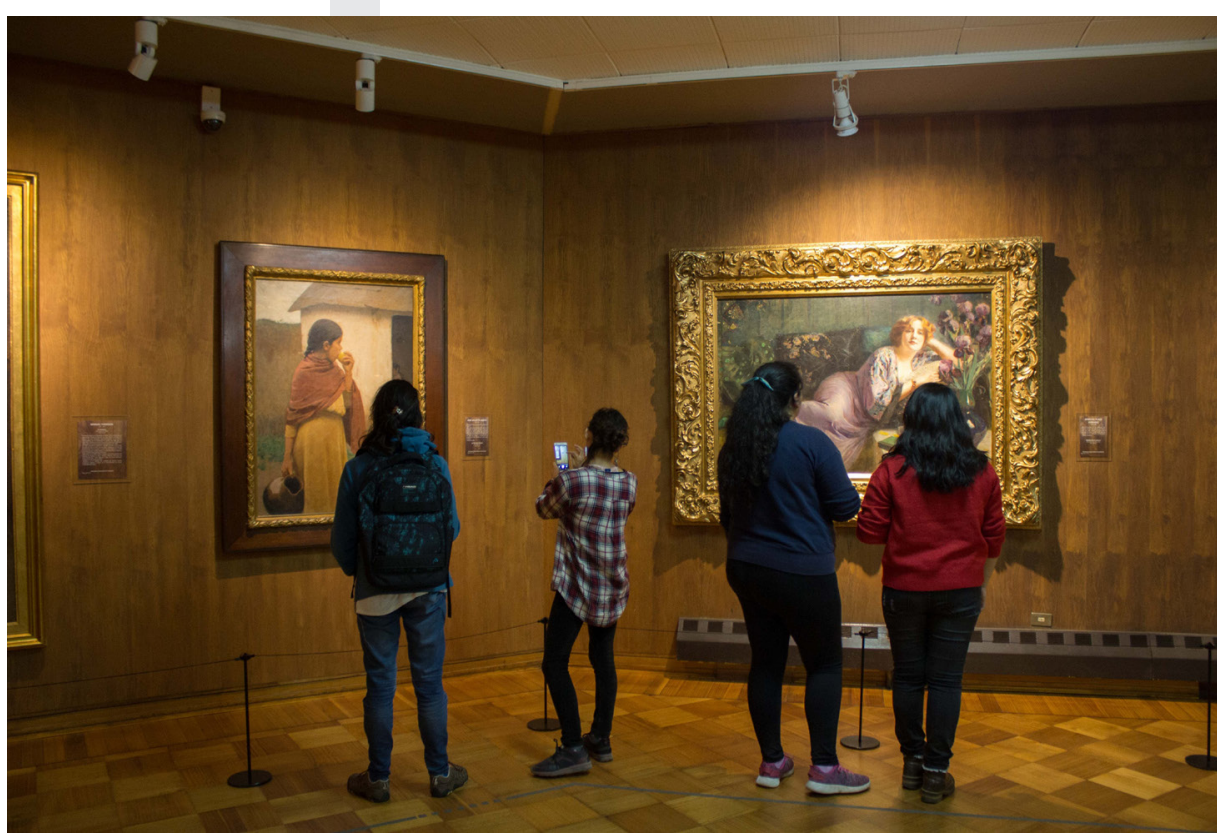

FOTO 4. Encuentro con los retratos de la colección permanente. homogéneos e inalterables, sino que proceden de la contradicción provocada en la tensión entre deseos y prácticas (Cabello \& García, 2011:83).

Esto implica tener en cuenta el devenir de los procesos de subjetivización identitaria atendiendo el "efecto de elecciones o selecciones de encajes y entrelazamientos [...] los flujos que circulan, se experimentan y delimitan relaciones y ensayos" (Tirado \& Domènech, 2008:59). Esto hace posible repensar las subjetividades como flujos continuos y extendidos a partir de decisiones, acciones y conexiones con el entorno sociomaterial. Por tanto, los retratos pictóricos pueden ser considerados como actores que se hacen parte de los procesos de subjetivización.

La ruptura de las dicotomías, ese lugar de apariencias e indeterminaciones que re-configuran la producción y reproducción de subjetividades, apelan a una interpretación que, alineada al cuerpo postmoderno, comienza a tomar

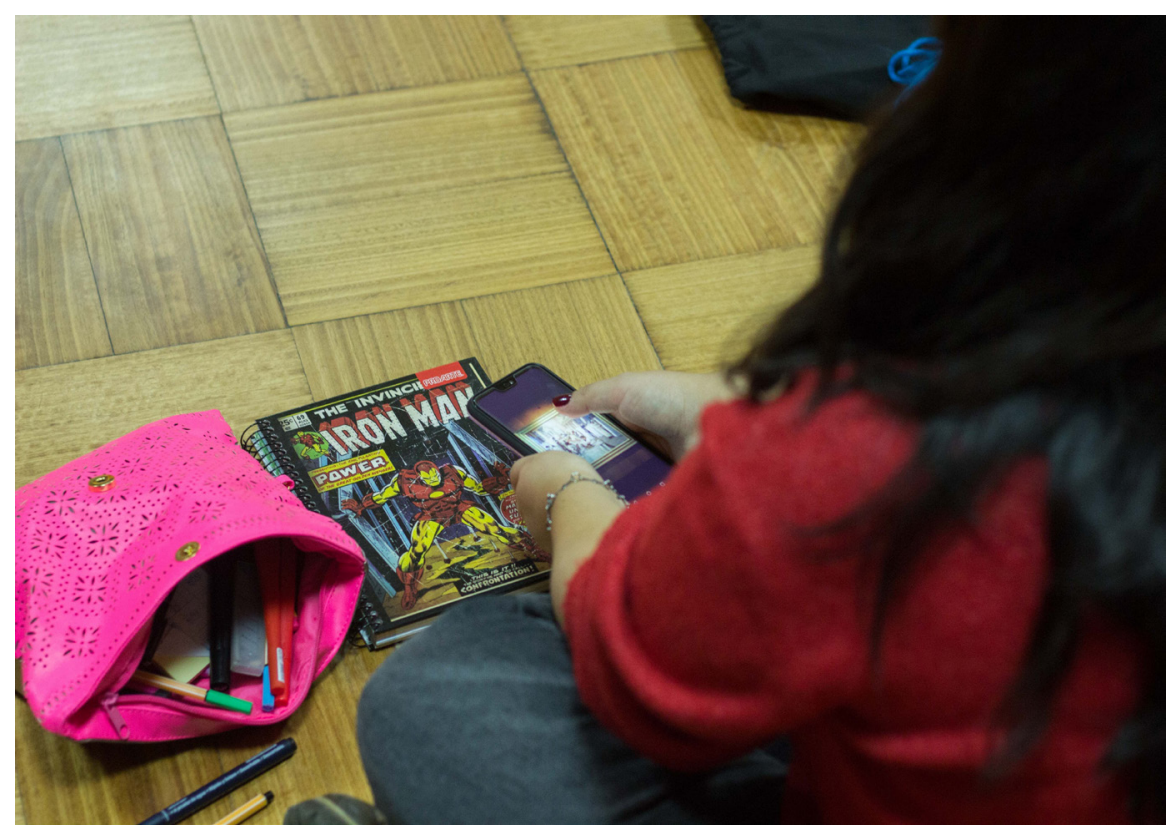

distancia de definiciones por caracteres de especie o género, sino que comienza a contar sus afectos (Deleuze \& Guatari, 2002:261). Por tanto, un examen de nuestros procesos de subjetivización identitaria, no debe restringirse a una revisión de las categorías que definen diferencias o similitudes reproducidas y organizadas jerárquicamente. Por el contrario, invita a explorar y seguir los flujos, circulaciones y tránsitos que son parte de nuestros procesos de subjetivización, esas mediaciones que también se establecen en base a conexiones con lo material y la agencia de las cosas (Hood \& Kraehe, 2017:33).

Nos desenvolvemos y nos relacionamos con objetos, tecnologías e imágenes, entidades cuyo análisis queda completamente sesgado y limitado si se les conceptualizara como intermediarios, volver a ellos y entenderlos como mediadores abre un campo de reflexión interesante (Tirado \& Domènech, 2008:65). Así, elementos de la cultura visual/ material, vídeos musicales, revistas, cómics, cine, publicidad, videojuegos, bellas artes, etc., pueden abrirnos un terreno fértil para explorar la configuración de subjetividades en términos identitarios, reflexivos y de (auto)conocimiento, pero asimismo, pueden conducirnos a la posibilidad de interrogar otros acervos que son parte de nuestra cotidianeidad y experiencia: la vigilancia, el control, el poder, la hegemonía, etc. Las mediaciones y el lugar de las cosas en la configuración de los procesos de subjetivización identitaria abre un campo de acción situado y encarnado

FOTO 5. Detalle de cosas que acompañan a una estudiante. 
en el que convergen dimensiones tanto materiales como inmateriales.

Si bien los retratos pictóricos se han abordado históricamente como elementos de representación, memoria y realidad de los cuales se han desarrollado interesantes análisis históricos, políticos y socio-culturales, resulta revelador ir más allá de esas concepciones que los sitúan, exclusivamente, como depositarios de géneros discursivos de carácter visual/ material o instrumentos sujetos a lecturas semióticas. El giro hacia lo material, es una invitación a detenernos a pensar en el poder de las cosas en la educación artística (Hood \& Kraehe, 2017:34) atendiendo como objetos no humanos median con nuestra experiencia encarnada, no únicamente ampliando la creación de sentidos, sino también, reconociendo los afectos de la identidad en la configuración de subjetividades en el entorno sociomaterial de la Universidad.

En definitiva, y con el objeto de alimentar el debate sobre otras formas de hacer y estar en la Universidad, es importante compartir la sensibilidad de desarrollar experiencias formativas más críticas, responsables, atentas y comprometidas con los entornos sociomateriales de los que somos parte. Este proyecto colaborativo expone cómo una práctica de indagación e intercambio, entre materialidad (retratos pictóricos, espacios, cartografías, etc.), docentes/ investigadores y estudiantes, posibilitó repensarnos en términos identitarios, poniendo sobre la mesa, una ética educativa y sociomaterial con la esperanza de proyectar una Universidad que resista a las lógicas del capitalismo cognitivo y artístico.

\section{Referencias}

Arfuch, L. (2005) Introducción. En: Arfuch, L. (Comp.) Identidades. sujetos y subjetividades $(13-20)$. Buenos Aires: Prometeo.

Ball, S. (1993). Foucault y la educación: disciplinas y saber. Madrid: Morata.

Bonino, L. (2003) Masculinidad hegemónica e identidad masculina. Dossiers feministes, 6, 7-36. Acceso enero 10, 2020, en http://www.e-revistes.uji. es/index.php/dossiers/article/view/735

Briones, C. (2007) Teorías performativas de la identidad y performatividad de las teorías. Tabula Rasa, 6, 55-83. Acceso noviembre 28, 2019, en http:// www.scielo.org.co/pdf/tara/n6/n6a04.pdf

Brubaker, R. \& Cooper, F. (2001) Más allá de "identidad". Apuntes de Investigación del CECYP, 7, 30-67. Acceso junio 03, 2020, en http://www. comisionporlamemoria.org/static/prensa/jovenesymemoria/bibliografia_ web/ejes/Brubaker-Cooper[definitivo].pdf

Cabello, A. \& García, A. (2011) Construyendo la masculinidad: fútbol, violencia e identidad. RIPS,10(2). Pp. 73-95. Acceso noviembre 24, 2019, en https://dialnet.unirioja.es/servlet/articulo?codigo=3669162

Cano, M. (2017). Políticas feministas no identitarias. La agencia desde la deconstrucción y la imperceptibilidad. Astrolabio. Revista Internacional de Filosofía, 19, 45-55. Acceso enero 11, 2020, en https://raco.pre.csuc.cat/ index.php/Astrolabio/article/view/318828

Cisterna, C., Soto, V. \& Rojas, C. (2016). Rediseño curricular en la Universidad de Concepción: la experiencia de las carreras de formación inicial docente. Calidad en la Educación, 44, 301-323. Acceso diciembre 06, 2019, en https://scielo.conicyt.cl/pdf/caledu/n44/art11.pdf
Deleuze, G. \& Guattari, F. (2002) Mil mesetas. Capitalismo y esquizofrenia. Valencia: Pre-Textos.

Fonseca, A. (2011). Metodologías participativas, subjetividades expandidas y transdisciplinariedad. Tesis psicológica: Revista de la Facultad de Psicología 6, 52-73. Acceso abril 19, 2019, en https://revistas.libertadores. edu.co/index.php/TesisPsicologica/article/view/245

Gergen, K. \& Gergen, M. (2011). Reflexiones sobre el construccionismo social. Madrid: Paidós.

Grau, M., Iñiguez, L. \& Subirats, J. (2010) La perspectiva sociotécnica en el análisis de políticas públicas. Psicología Política, 41, 61-80. Acceso diciembre 16, 2019, en https://www.uv.es/garzon/psicologia\%20politica/ N41-4.pdf

Guattari, F. (1992) Caosmosis. Ediciones Manantial: Buenos Aires.

Hernández, F. (2006) Campos, temas y metodologías para la investigación relacionada con las artes. En: M. Gómez, F. Hernández \& H.J. Pérez Bases para un debate sobre investigación artística (9-50). Madrid: Secretaria General Técnica. Subdirección General de Información y Publicaciones.

Hernández, F. (2018). Encuentros que afectan y generan saber pedagógico entre docentes a través de cartografías visuales. Revista Digital do LAV, 11(2), 103-120. Acceso junio 20, 2019, en https://periodicos.ufsm.br/ revislav/article/view/33898

Hernández, F. \& Miño, R. (2012). Indagar sobre las concepciones de los estudiantes en torno a la experiencia de aprendizaje autónomo. Revista del Congrés Internacional de Docència Universitària i Innovació (CIDUI), 1(1),115. Acceso noviembre 28, 2019, en https://www.cidui.org/revistacidui/ index.php/cidui/article/view/29

Hood, E. \& Kraehe, A. (2017). Creative Matter: New Materialism in Art Education Research, Teaching and Learning. Art Education, 70(2), 32-38. Doi: http://dx.doi.org/10.1080/00043125.2017.1274196

Martínez, J. (2014). La universidad productora de productos: entre biopolítica y subjetividad. Bogotá: Universidad de la Salle.

Martín-Barbero, J. (2003). Saberes hoy: diseminaciones, competencias y transversalidades. Revista Iberoamericana de Educación, 32, 17-34. Acceso enero 19, 2020, en https://rieoei.org/historico/documentos/rie32a01.pdf

Montenegro, M. \& Pujol, J. (2013). La fábrica de conocimientos: in/ corporación del capitalismo cognitivo en el contexto universitario. Athenea Digital, 13(1), 139-154. Acceso noviembre 28, 2019, en https://doi. org/10.5565/rev/athenead/v13n1.1031

Rancière, J. (2010). El espectador emancipado. Buenos Aires: Manantial.

Restrepo, E. (2014) Sujeto e identidad. En: E. Restrepo (Coord.) Stuart Hall desde el sur. Legados y apropiaciones (97-118). CLACSO: Buenos Aires.

Susinos, T. \& Parrilla, T. (2013). Investigación inclusiva en tiempos difíciles. Certezas provisionales y debates pendientes. REICE Revista Iberoamericana sobre Calidad, Eficacia y Cambio en Educación 11(2), 87-98. Acceso junio 06, 2019, en https://revistas.uam.es/index.php/reice/article/view/2898

Tirado, F. \& Domènech, M. (2008). Asociaciones heterogéneas y actantes: El giro postsocial de la teoría del actor-red. En: T. Sánchez-Criado (Ed.) Tecnogénesis. La construcción técnica de las ecologías humanas (41-78). Madrid: AIBR.

Van Manen, M. (2003). Investigación educativa y experiencia vivida. Ciencia humana para una pedagogía de la acción y la sensibilidad. Barcelona: Idea Books.

Walsh, C. (2014). Lo pedagógico y lo decolonial: Entretejiendo caminos. Querétaro: En cortito que's pa' largo. 